\title{
Heat Pump Technology Applies on Air-conditioners Impact on Electric Power
}

\author{
Kun Liu, Xiaoyan Zhou, Hailang He \\ School of Electrical Engineering, University of Southwest Jiaotong, Sichuan, China \\ Email: liukun12031112@163.com
}

Received March, 2013

\begin{abstract}
In recent years, power grid has been experienced in difficult times that there is a shortage of demand load among market, and more and more black out exited that bothered residents' normal life. With the increment of energy consumption and power load, this problem will be more serious without any feasible solutions. Besides, the air conditioning system is the largest residential energy consumer. In this report, a GSHP air conditioning system has been illustrated and compared with the conventional air conditioning system currently used in Chengdu, Sichuan province, China. The benefits of using the GSHP system are not only on cost saving, but also energy saving and eco-friendly.
\end{abstract}

Keywords: GSHP; Air Conditioning; Energy Saving; Cost Saving

\section{Introduction}

Heat pump technology has been widely used on different fields in most western countries for a long time, such as in Norway, the United States of America and so on, but this technique is still fresh to Chengdu, China, especially in air-conditioner industry, which has proven to be the most electricity consume electronic among the lives of local residents. The whole world is walking at a high speed of energy consumption[1].In this article, the analysis of the heat pump air-conditioners will be talked about to determine whether it is a better system for the residents, the power company. The main aims of this project is to determine whether the heat pump air-conditioner system can consume less electricity when compared with the conventional air-conditioners used in Chengdu, in this situation, electric refrigeration heating air conditioners. If it is, how much electricity can be saved and how much money customers can save by heat pump air-conditioner.

\section{Background}

As the electricity energy is one of the most important parts of energy resources, it plays a critical role in people's living standard and productivity. As the International Energy Agency mentioned[2], it has come to a very dangerous situation for the lack of energy resources. Nowadays, there is a crisis of energy shortage in the world, especially the shortage of power resources. According to the concerning material record by the State
Grid Corporation of China (SGCC)[3], there were more than 21 main large cities in China experienced black-out because of the restriction of power, on the other words, the lack of electricity offered by the power company in 2003, where Chengdu was one of these cities. This action did a serious negative impact on the residents "living standard and enterprises"' normal production. Due to the electricity survey report 2009 from the Sichuan power grid. This big client occupied about $35 \%$ to $40 \%$ of the total residential electricity consumption[4]. So if there is a better solution which could make the residential air-conditioner system consumes less electricity, there will be a great help to reduce the burden from power grid, and make a contribution to the highlighted energy saving issue.

\subsection{Electrical Consumption in Residents' Life}

In recent years, as residents' living standards improved, the increment of the income of urban and rural residents, and the update and popularize of all kinds of household appliances, there is a remarkable rise of electricity consumption by residents living, so is the proportion of total electricity consumption. In 2007, residents' electricity consumption in Sichuan is $16098.38 \mathrm{GW} / \mathrm{h}$, occupied $13.7 \%$ of the whole society total power consumption[5], where the consumption from urban residents was $9044.97 \mathrm{GW} / \mathrm{h}$, account for $56.19 \%$ of the sums Reasons that caused by the rapid increment of the residents' energy consumption are various, such as the rapid increase in population; the increase of the household's income 
and the larger ownership of the electronic equipment. Among the equipment, the significant one that leading to the swift growth of electricity consumption could be sharply increase of ownership of the air-conditioners in households.

\subsection{Results Gained by Air Conditioning Energy Saving Actions in Chengdu}

Since 2003, because of the rising intension condition of power supply in China[3],the Chinese government started to promote electrical demand side management (DSM). In 2004, the National Development and Reform Commission (NDRC) and the State Electricity Regulatory Commission (SERC) issued jointly $<$ Guidance for strengthen the power demand side management $>$ to support DSM action. In 2007, General Office of the State Council released $<$ Notification about strictly execution of air-conditioning temperature control standard in public buildings > ([2007] NO.42) to regulate air-conditioning saving management.

Chengdu government and power grid worked together to organize a series of actions on cooling load demand side management in summer to control the cooling load. In order to reduce the energy burden, Chengdu power grid encouraged their customers to choose a new style of air-conditioners to save more electricity with lower electricity price, this may help avoiding the appearance of black out. This action has acquired preliminary achievements by some commercial customers, but met limited excitement with residential customers[4].

\section{Theory}

In this section, all theories and applications will be expounded specifically. And heat pumps air-conditioners are considered to replace conventional air-conditioners in order to reduce the consumption of the electricity in the Sichuan power market, the reduction of the energy consumption will not only contribute to protect the power grid to avoid black out, but also bring a financial benefits to those customers for their electricity bills.

Ground source heat pump systems are based on the shallow geothermal of rock and earth mass, ground water and surface water as resources for both heating and cooling $^{[6]}$. This is a new central air conditioning system that depends on renewable resources for both heating and cooling and can meet the achievement of "energy saving and emission reduction”.

\subsection{The Components and Features of GSHP}

Ground source heat pumps are consisting of water-source heat pump unit which can provide cooling or heating to the buildings, a shallow geothermal heat exchanging system and a central air conditioning system in the inte- rior of the buildings. There are three types of GSHP due to the different heat transfer medium, they are Ground water heat pumps, Surface water heat pumps, and Buried pipe Ground source heat pumps. Heat pump units can also divide into two types by methods of operation, screw heat pump units and water switch heat pump units. In this project, air-conditioners are used for the central air-conditioning system for the whole community, therefore screw heat pump units is more suitable than the other one for cooling and heating[7]. This system features characteristics as shown below[6]:

- Ground source heat pump technology is a technology with high efficiency energy saving, non-pollution, and low cost of the operation which relies on shallow geothermal resources for both cooling and heating. Not only for air conditioning, can it also supply hot water for residents" living. It has been referred as the "Green air conditioning technology" in the 21st Century. Currently, there are two types of GSHP in air conditioning market, they are ground water technology and buried pipe ground source technology.

- Ground source heat pump has the ability to reduce the emission of greenhouse gas sharply. As most of the resources are coming from the underground soil when the GSHP system generates heating in winter, less than half resources are generated by electricity. Hence it can be used instead of a heating boiler, so that there could be approximately $70 \%$ of greenhouse gas emission reduced for the environment. Moreover, there is no need for any special geothermal field or geothermal water to apply for the system, normal soil (over $-3.5^{\circ} \mathrm{C}$ ) can meet the technical operation conditions of GSHP. Meanwhile, it will not pollute and deplete the underground water.

- GSHP uses renewable resources; there is no resource exhaustion problem for this technology.

- High efficiency but low cost. For heating, the coefficient of performance (COP) could reach at most of 5.0, but this of the normal boiler is only between 0.7 and 0.9 , $70 \%$ of energy can be saved and there is also about half reduction of the operation cost. For cooling, the conventional electrical refrigeration air-conditioners spend $40 \%$ of energy more than GSHP, which could make the electrical bill more expensive. Hence, there is an economical benefit while using GSHP.

\subsection{Economic Efficiency and Energy Conservation of GSHP}

- Ground source heat pump can work together with an energy storage device to realize propose of electricity load shifting suggested by the power grid company. A battery can store electricity during the off-peak time, which is at a very low price compare with peak time. In this situation, customers can save much money on elec- 
tricity bill and the power grid gets protected at the same time.

- During the summer time, units can recover heat from condenser by the heat recovery switch, heating living water for free. Furthermore, the tropical island effect can be avoided by not using the cooling tower for the system.

- The COP of GSHP can be very high compared with conventional air-conditioners. COP of GSHP for heating can reach 5.0 at most and even achieve 6.0 for cooling, where conventional system can only reach up to 3.5.The method to calculate Coefficient of Performance ${ }^{[6]}$ : COP = $\mathrm{Q} / \mathrm{W}$,

Where Q: delivered heat; W: electricity consumption of the heat pump. To determine the benefits that obtain by a GSHP system could come after by following processes.

\subsection{Previous GSHP Air-conditioning Case in Chengdu}

In 2005, Long Jin community had been selected to be the first residential community to use the GSHP system for the air-conditioning. Due to the limited conditions of itself, only two buildings can apply for the GSHP central air conditioning system. Residents in these two buildings can choose either GSHP system or conventional split type air-conditioners.According to the feedback report[8],customers received a $40 \%$ less electricity bill on operation cost of GSHP compared with conventional systems. Especially when the temperature was over $35^{\circ} \mathrm{C}$, the gap between these two systems became larger, up to $70 \%$.

Overall, customers who chose Ground source heat pump as air-conditioners saved 2424 (Yuan) than customers who consisted using conventional air-conditioners for a year. As the capital cost of GSHP air-conditioners is 8000 (Yuan) more than conventional air-conditioners, so the GSHP's customers recovery cost after 3 years and a half.End-users can make this goal by changing their electricity consumption patterns in several approaches such as adjusting their air-conditioners level[9].

\section{Figures and Tables}

In this section, the operation cost of GSHP air-conditioners and conventional spilt-type electric refrigeration and heating air-conditioners will be discussed here. These two systems should operate under all conditions below:

1) For the GSHP system, equipment will operate 90 days in summer (from mid-June to mid-September) and 60 days in winter (From mid-December to mid-February).

2) Air-conditioners will start to work at 11 am until 21 pm, ten hours working every day. This system should continuously work even in the peak time; hence there is a four-hour peak demand.

3) All system holds a full load operation rate at 0.6.

4) The utilization rate for summer and winter is 0.8 and 0.7 respectively.

The operation fee can be calculated by this equation: Operation Cost $=(\mathrm{L} * \mathrm{P} * \mathrm{~T}+\mathrm{L} * \mathrm{Ps} * \mathrm{~N}) * \mathrm{D} * \mathrm{O} * \mathrm{U}$ Where, L represents power input load;

$\mathrm{P}$ represents the electricity price at peak time;

Ps represents the standard electricity price;

$\mathrm{T}$ represents the system working time at peak load;

$\mathrm{N}$ represents the rest operation time;

$\mathrm{D}$ represents the working days of system;

$O$ represents the full load operation rate;

$\mathrm{U}$ represents the system utilization rate.

Referring to the running output of this programming, we can get that operation fees in both summer and winter for these two systems as shown in "Table 4.1".

As shown above, it can be clearly seen that the annual operation cost of conventional system is much expensive than GSHP system, customers will spend 130,440 Yuan (about 0.027 Yuan per square meter per day) more for the conventional system every year.

Besides, The power input of the GSHP system is less than $1000 \mathrm{~kW}$, in this situations, the air conditioning system only requires a $1000 \mathrm{KV}$ transformer. But the conventional system asks for more power to operate, hence only one $1000 \mathrm{KV}$ transformer is not satisfied the maximum demand; therefore, there could be a big difference between the costs of the power supply system and maintenance fees for these two systems.

From "Table 4.2”, it shows that for the power supply system, for the initial investment of the GSHP system, there will be 300,000 Yuan less than conventional system for the power supply system; and in the following ten or even twenty years, there will also be 50,000 Yuan less in maintenance cost each year.

The total cost of these two systems can be seen in “Table 4.3”. This could be a distinctly comparison between GSHP system and conventional system.

The economic trend of these two systems can be seen in "Figure 4.4".

Table 4.1. Annual operation cost for both systems.

\begin{tabular}{lcc}
\multicolumn{1}{c}{ Annual Operation } & GSHP system & Conventional system \\
\hline Summer & 241,520 & 342,900 \\
Winter & 209,630 & 238,690 \\
Annual total cost (Yuan) & 451,150 & 581,590 \\
$\begin{array}{l}\text { Per square meters cost } \\
\text { (Yuan) }\end{array}$ & 0.094 & 0.121 \\
\hline
\end{tabular}


Table 4.2. Capital cost of air conditioning power supply system.

\begin{tabular}{lcc}
\hline \multicolumn{1}{c}{ (Yuan) } & GHSP system & Conventional system \\
\hline 1000KV transformer required & 1 & 2 \\
Cost of transformer & 300,000 & 600,000 \\
Maintenance fees(per year) & 50,000 & 100,000 \\
Capital cost saved & & 300,000 \\
Maintenance cost saved & & 50,000 \\
\hline
\end{tabular}

Table 4.3. Total cost for GSHP system and conventional system.

\begin{tabular}{lcc}
\hline \multicolumn{1}{c}{ Cost items } & GSHP system & Conventional system \\
\hline $\begin{array}{l}\text { Equipment capital cost } \\
\begin{array}{l}\text { Power supply system } \\
\text { equipment cost }\end{array}\end{array}$ & $5,315,000$ & $3,840,000$ \\
$\begin{array}{l}\text { PS system maintenance } \\
\text { cost (per year) }\end{array}$ & 500,000 & 600,000 \\
\begin{tabular}{l} 
Operation cost (per year) \\
\hline
\end{tabular} & 451,150 & 100,000 \\
\hline
\end{tabular}

In "Figure 4.4", it can be seen that in the first five years, the cost of GSHP is higher than conventional system, but when both system work in the middle of the fifth year, the GSHP system begins to show its' own economic advantage. Suggest both systems have 20 years lifetime, customers who choose the GSHP system only pay 14,783,000 Yuan in total, but customers still consist using the conventional air conditioning system will spend more than 18,000,000 Yuan. With the latest survey for the lifetime of split-type electric refrigeration and heating air-conditioner is normally five to seven years. So after this period of time the air-conditioners should be replacing by new systems, this will cause a large increment of the capital cost of conventional system.

Besides, with the GSHP system, plenty of electricity can be saved under the operation of this system when compared with the conventional system. In this case, the reduction of power demand from customers will decrease the instability factor which could give a dangerous impact on the power grid.

According to "Figure 4.5", each year, there can be more than $0.4425 \mathrm{GW} / \mathrm{h}$ energy consumption saved by the GSHP system when compared with the currently conventional system. Assuming run both systems for 20 years, there will be approximately $8.85 \mathrm{GW} / \mathrm{h}$ consumption saving operating under the GSHP system. This significant number will give a great help for Power Company to offer a stable network to the public.

\section{Conclusions}

This Article has suggested a newly GSHP technology applied on the air conditioning system to replace the conventional split-type electrical refrigeration and heating air-conditioners. For power grid, GSHP system can reduce $0.4425 \mathrm{GW} / \mathrm{h}$ energy consumption every year, leave totally $8.85 \mathrm{GW} / \mathrm{h}$ free electricity away in the market in 20 years. Under the circumstances, it vigorously protect the power grid, brings a more stable and reliable power system for the market.

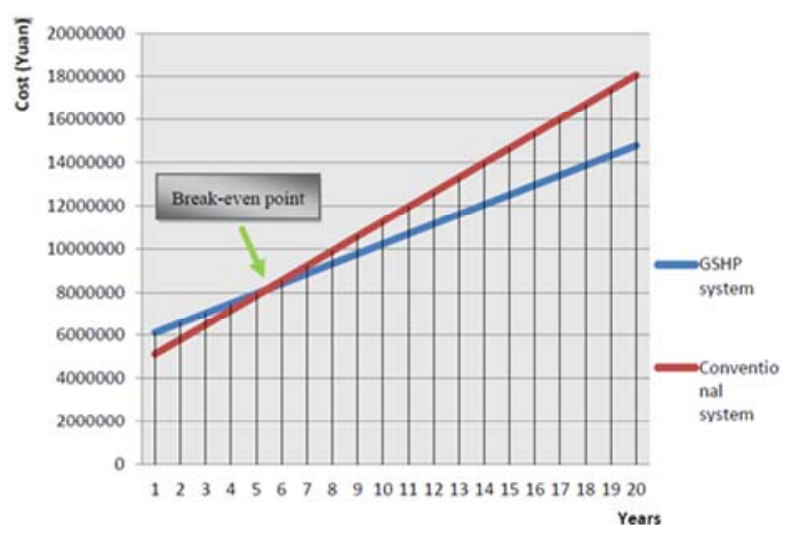

Figure 4.4. Economical effects of both systems in 20 years.

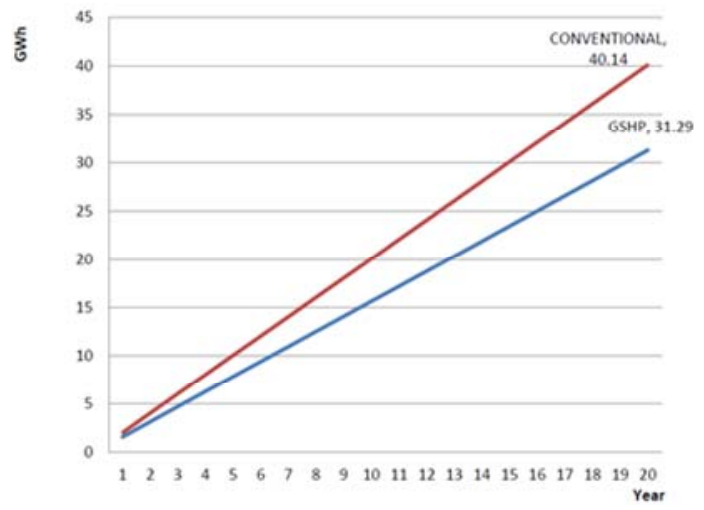

Figure 4.5. power consumption of both systems.

\section{Future Work}

There is a system called "ice storage air conditioners" existed in the market, but this technology does not have the heating function, so would it become more efficient if it do have both heating and cooling functions in the future? Whether this system can save more energy and cost with a reliable and stable market?

That is what I want to go furthermore if I have more time and resources.

\section{REFERENCES}

[1] F. Q. Zhou, “Challenge posed to China’s energy industry 
in the 21st century," Heating Ventilating \& Air Conditioning," Vol. 30, No. 4, 2000, pp. 23-25.

[2] IEA, “The World Energy Outlook,” London: IEA press.

[3] SGCC, Annual Report of Electricity Demand and Consumption in Sichuan, Sichuan Power Grid, 2012.

[4] H. Q. X, China Energy Development Report, Beijing: China Environmental Science Press, 2006.

[5] SGCC,Electricity competitiveness research report in Sichuan terminal energy consumption market,Sichuan Power Grid.

[6] D. Banks, "An Introduction to Geothermal: Ground Source Heating and Cooling,” Blackwell, 2008. doi:10.1002/9781444302677

[7] J. G. Wang, J. Liu and L. G. Kang, “The Feasibility of the Use of Composite Ground Source Heat Pump in hot summer and Cold Winter Region,” International Conference on Services Science, Management and Engineering,2009.

[8] Chengdu Cu Jin real estate, Chengdu Long Jin: GSHP System Operation Technical and Economic Analysis, Architectural Technology, Vol. 12, 2006, pp. 26-27.

[9] D. Yang and Y. Chen, "Demand Response and Market Performance in Power Economics,” power and energy meeting,2009. 